\title{
O SISTEMA DE REGRAS EM HERBERT HART
}

\author{
Vitor Hugo Duarte das Chagas*
}

\section{RESUMO}

Este trabalho possui como objetivo analisar bibliograficamente o conceito de Direito de Herbert Hart como um sistema de regras primárias e secundárias, portanto, é feita uma análise da filosofia analítica da linguagem, que influencia o pensamento de Hart. Após, o foco é nas críticas a John Austin para a partir delas chegar ao modelo de regras. Ao final, o trabalho mostra como Hart vê a relação entre essas regras seus conceitos de regras primárias e secundárias. Finalmente, o trabalho mostra como fundamento do Direito na concepção hartiana se baseia em um sistema de regras interdependentes.

PALAVRAS-CHAVE: prática, sociologia, regras, sistema, validade, reconhecimento.

\section{THE HERBERT HART'S RULES SYSTEM}

\begin{abstract}
This work aims to analyze bibliographically the model by which the English jurist Herbert Hart arrived at his concept of Law as a system of primary and secondary rules, therefore, the work shows how the analytical philosophy of language influences on Hart's thoughts. Then, Hart's critics on John Austin in order to make Hart's rules model. In the end, the work shows how Hart sees the relationship between these rules and his concepts of primary and secondary rules. Finally, the work shows how Hart thinks in an interdependent rules system as Law basis.
\end{abstract}

KEYWORDS: practices, sociology, rules, system, validity, recognition.

\section{INTRODUÇÃO}

O presente trabalho possui como objetivo explicar conceitos fundamentais na teoria analítica do Direito Anglo-Saxão, que são os conceitos de regras secundárias e regras de reconhecimento, presentes na obra o Conceito de Direito de Herbert Lionel Adolphus Hart. Sendo ele o grande autor tomado como referência para a teoria do Direito analítica anglo-saxã feita posteriormente o toma como referência, seja para usar como base e aprimorar, ou seja para criticá-lo.

\footnotetext{
* Advogado, Bacharel em Direito e Mestrando em Direito, Desenvolvimento Regional e Políticas Públicas pelo Centro Universitário do Pará. E-mail: vitor.chagas00@gmail.com.
} 
Inicialmente, será exposta a influência da filosofia analítica da linguagem no pensamento de Herbert Hart e de seus contemporâneos ingleses teóricos do Direito. O grande nome da filosofia da linguagem é Ludwig Wittgenstein, que teve influência no pensamento de Herbert Hart, especialmente o chamado Segundo Wittgenstein. J. L. Austin é contemporâneo de Hart e também o influencia na forma como a sua concepção de significado influencia na ideia de Direito.

O trabalho tentará situar a visão de Hart sobre o Direito, com ênfase nas críticas a John Austin. O trabalho elucidará a forma como Hart vê como simplista reduzir o conceito de Direito a um conjunto de comandos e hábitos para posteriormente mostrar-se como Hart vê o Direito, de fato, como um conjunto de regras. E como esse conjunto de regras é o que é realmente importante para uma definição analítica do Direito.

Para Hart, o modelo de Austin é atraente justamente por ser um modelo que é simples e direto ao reduzir o conceito de Direito aos conceitos de ordem e de ameaça. É sobre esses conceitos que Hart se dedica a fazer uma crítica bem detalhada ao definir seu produzir o seu conceito de Direito analítico.

O trabalho procura elucidar de que maneira Hart constrói o seu conceito de Direito não voltado a entendê-lo e defini-lo somente como norma ou regra jurídica, mas sim como um complexo sistema de regras interrelacionadas, partindo de regras primárias e regras secundárias. O objetivo é mostrar como Hart fundamenta seu sistema.

É nesse ponto que a definição de Direito hartiano ganha destaque e se diferencia dos demais estudos de Direito. Enquanto na tradição romano-germânica de Civil Law, a base do entendimento do Direito positivo é Hans Kelsen, que definiu o objeto do estudo do Direito como a norma jurídica.

Portanto, o objetivo deste trabalho é fazer uma análise de como Herbert Hart desenvolveu o seu conceito de Direito e formou o fundamento ao seu sistema jurídico. Serão analisados as suas influências, o objetivo com que Hart escreveu e como ele chegou às conclusões sobre o problema que expôs.

\section{A INFLUÊNCIA DA FILOSOFIA DA LINGUAGEM NO PENSAMENTO DE HERBERT HART.}

Herbert Hart (2009) faz parte da chamada Teoria do Direito analítica, que consiste e identificar e, após isso, elucidar os conceitos do Direito. Ele ocupou a cátedra de Direito em 
Oxford, Inglaterra, e ao desenvolver seu conceito de Direito teve contato com pensadores da chamada filosofia da linguagem comum, ou Escola de Oxford, como seu colega contemporâneo John Longshaw Austin (1982).

Hart (2009) define o seu método de análise do Direito como uma sociologia descritiva, termo que nesse sentido não é utilizado para afirmar que Hart teria filiação a um método sociológico ou a alguma escola própria da Sociologia enquanto área do conhecimento, mas sim que a análise de Hart (2009) traz características referentes a práticas sociais que fazem parte do Conceito de Direito que ele pretende desenvolver. Hart (2009) analisa como essas práticas fazem parte dos fenômenos jurídicos.

\begin{abstract}
Apesar de sua preocupação com a análise, o livro pode também ser encarado como um ensaio de sociologia descritiva, pois a ideia de que a investigação sobre os significados das palavras lança luz apenas sobre estas é falsa. Muitas distinções importantes entre tipos de situações e relações sociais, que não são óbvias à primeira vista, podem ser elucidadas mediante um exame dos usos convencionais das expressões conexas e da maneira como estas dependem de um contexto social, que permanece ele próprio frequentemente implícito. Neste campo de estudo, é especialmente verdadeira a afirmação de que podemos utilizar, "uma consciência mais aguda das palavras para aguçar nossa percepção dos fenômenos". (HART, 2009 , p. X)
\end{abstract}

De acordo com Coterrell (1989), a sociologia de Hart possui a particularidade de descrever o modo como os juristas e os leigos usam a linguagem do Direito. De acordo com Stolz (2007), Hart entende a filosofia analítica como o método que permite não somente sopesar significados de expressões, mas também entender melhor o funcionamento das instituições sociais e, em particular, o Direito.

A filosofia da linguagem usada como método por Hart influencia situações e relações sociais envolvidos nos contextos e no uso das palavras, de uma forma que não se conseguiria fazer na observação direta das práticas sociais. O exame indireto, feito por meio da linguagem, traz à tona sutilezas ocultas e pressupostos não explícitos, que só deixam rastros no modo como usamos as palavras e que, portanto, atua como um tipo complementar de sociologia descritiva, uma que pudesse descrever práticas sociais não por um método, mas sim feito por uma análise linguística.

Essa corrente filosófica acreditava que problemas filosóficos poderiam ser mais apropriadamente solucionados pelo uso de esclarecimentos linguístico-conceituais. Portanto, seu método consistiria em destrinchar os conceitos importantes em uma determinada abordagem e enumerá-los para após delimitar o sentido de cada um deles. 
Para a filosofia analítica, conceitos fazem parte da atividade comunicacional, logo, são entidades da linguagem. O sentido de um conceito é analisado pela linguagem com o objetivo de resolver seus problemas filosóficos.

Ludwig Wittgenstein (2008), em sua obra "Investigações Filosóficas", afirma que a linguagem não é apenas uma forma de representação e nomeação das coisas que estão no mundo. De fato, ela seria uma maneira de se comportar e reagir às diferentes situações do cotidiano.

Em “Tratado Lógico-Filosófico", Wittgenstein (2002) afirma que todo tratado sobre teoria da linguagem deve necessariamente ter uma teoria da realidade. Sendo a linguagem uma representação do mundo real, Wittgenstein (2002) afirma que o pensamento é uma proposição com sentido, e essas proposições unificadas formariam a linguagem como um todo. Desse modo, a linguagem é uma tradução da realidade.

Wittgenstein (2002) chega a afirmar que todos os problemas filosóficos envolvem linguagem, e que por isso toda filosofia é crítica da linguagem. Ele afirma que se existe algo que não possa ser expressado e traduzido por meio da linguagem, não está no mundo e por isso não pode ser problema da filosofia. Portanto, o entendimento de linguagem é capaz de resolver as questões propostas por filósofos, o que Wittgenstein (2002) compreendia como uma compreensão defeituosa do funcionamento da linguagem.

Wittgenstein (2008) expande sua visão sobre a linguagem em "Investigações Filosóficas" de modo que sua visão sobre a linguagem assume um papel transcendente, isto é, é parte fundamental do interagir humano, funciona como respirar ou alimentar-se, estando presente em uma grande pluralidade de ações. Para ele, conceber um tipo de linguagem significa conceber uma forma de vida.

Para J.L. Austin (1982), linguagem e ação estariam estreitamente ligadas, mais ainda, toda linguagem estaria conectada a uma prática social. O significado de uma expressão linguística somente pode ser extraído a partir de expressões fundadas no plano concreto, isto é, não há um significado pautado em idealismo para a linguagem, ela precisa estar conciliada ao plano prático. Todo significado de palavras remete à prática com que essa linguagem se associa.

J.L. Austin (1982) afirmava que definir o conceito de "promessa" seria inútil para se entender plenamente o que são promessas. Um verdadeiro entendimento ocorreria quando se explicasse o ato de se fazer promessas e quais seriam suas consequências práticas. $\mathrm{Na}$ 
concepção de Austin (1982), ao analisar corretamente o conceito de promessa, não se está destrinchando uma palavra, mas sim o contexto em que se fez uma promessa e quais consequências essas promessas acarretam sobre situações e relações sociais. É justamente o tipo de análise feita por Hart (2009), que ele mesmo denominou de sociologia descritiva.

Em seus comentários ao primeiro capítulo, Herbert Hart (2009) faz referência à influência de Wittgenstein:

A compreensão das diferentes maneiras pelas quais os vários usos de um termo geral
podem estar relacionados é de especial importância no caso de termos jurídicos,
morais e políticos. (...). Sobre a noção de "semelhança de família": ver Wittgenstein,
Philosofical Investigations, i, §, 66-76. Conforme Capítulo VIII, s.1, sobre a
estrutura do termo "justo". O conselho de Wittgenstein (op. cit. §66) é
particularmente pertinente para a análise dos termos jurídicos e políticos.
Considerando a definição de "jogo", ele disse: "Não diga que é imprescindível haver
alguma coisa em comum, ou senão eles não seriam chamados "jogos', mas olhe e
veja se há algo comum a todos. Pois, se você os observar, não verá nada comum a
todos, mas apenas semelhanças, relações, aliás toda uma série destas". (HART,
2009, p. 360).

De acordo com Peruzzo Júnior (2018), Hart entende o Direito como uma prática social, em que o critério de validade consiste em um comportamento social estabelecido pela normatividade das regras.

O estabelecimento de uma divisão de diferentes tipos de regras feitas por Hart funciona através do conceito wittgensteiniano de semelhanças de família, sem conceitos amplos que poderiam facilmente apoiar a dedução de sua interpretação e consequentemente funcionar denotativamente.

De acordo com Wittgenstein (2008), jogos de tabuleiros possuem diversas semelhanças entre si, jogos como Xadrez, Damas e outros esportes em geral podem ser definidos por estabelecer semelhanças e diferenças. São as formas que ele encontra de analisar que nas relações humanas existe um rede de semelhanças que se cruzam mutuamente, em conjuntos e detalhes.

Assim como nos jogos exemplificados por Wittgenstein (2008), não existe uma essência única nas mais plurais formas de linguagem. $O$ que existiria na linguagem são semelhanças de família que mudariam com tempo e o espaço, guardando somente alguns traços que podem ser relacionados.

De acordo com Pablos (2013), Hart segue a ideia de semelhança de família em Wittgenstein porque Hart através de sua visão do Direito, afirma que não é necessária delimitação rígida para os termos da linguagem ou o conhecimento de todas as normas 
jurídicas previamente à sua aplicação para que o Direito possa ser entendido como uma ciência normativa e exata. É possível saber qual seriam as finalidades do uso de regras ao considerar seu contexto de aplicação. Faz-se uma semelhança de famílias, sem necessariamente buscar-se uma essência de uma linguagem rígida no estudo do Direito.

Ao renunciar a uma concepção de significado como uma ideia que existe por si mesma e está inerentemente associada com certo termo em favor de uma concepção de que o conjunto de significados de uma palavra é, em verdade, o conjunto dos usos palpáveis que essa palavra pode ter em diferentes contextos. Hart se aproxima do conceito de semelhanças de família wittgensteiniano.

Para Hart (2009), para compreender-se a ideia de como deve ser compreendido o funcionamento do Direito e quais seriam os conceitos próprios desse Direito, deve-se analisar a maneira como esses conceitos são utilizados na prática. O conceito de coerção deve ser analisado sob a perspectiva de forma a se perguntar sobre a situação em que alguém é coagido, deve-se pensar em uma situação em que alguém foi coagido. Quando se quer analisar uma regra, deve-se imaginar a situação em que se afirma como exemplo de uma regra.

Se o significado é estreitamente atrelado à prática, esclarecer o seu significado é esclarecer a sua prática. O uso da linguagem não é um grito no vazio, é, em verdade, dependente do contexto em que se usa a linguagem. Portanto, é inegável a influência de Wittgenstein (2008) no pensamento de Herbert Hart (2009).

Dessa maneira, a conexão entre a jurisprudência analítica e a sociologia descritiva se dá na medida em que a análise dos conceitos descrevem as práticas sociais. O estudo dos conceitos do Direito deve estar alinhado a uma abordagem prática e assim se distanciar de uma visão meramente abstrata.

É seguindo essa linha que Hart (2009) desenvolve o primeiro capítulo do seu livro, em que apresenta uma pluralidade de conceitos que podem ser dados ao Direito. A ideia de Hart (2009) afirma que essas abstrações somente podem ser levadas a sério se puderem responder dificuldades práticas do Direito, portanto, Hart (2009) tenta explicar de que forma a obrigação jurídica se difere do conceito de coerção, de como a obrigação jurídica se difere da obrigação moral e sobre o que seriam os conceitos de regras.

Conforme explica Stolz (2007), Herbert Hart procura desenvolver inicialmente sua abordagem de o Conceito de Direito seguindo a ideia de responder à questão sobre o que seria 
o Direito. Segundo ela, para encarar esse questionamento seria necessário saber respectivamente em que se diferenciaria o Direito das ordens respaldadas por ameaças; em que se distingue a obrigação jurídica da obrigação moral; e o que seriam as normas e em que medida o Direito seria formado por um conjunto de normas. Os problemas jurídicos residiriam em detalhar as relações entre o Direito e a coerção, o Direito e a Moral e entre Direito e Regras.

Para responder parte dessas indagações, Hart (2009) e exemplifica como pode se utilizar da influência da filosofia da linguagem para fazer sua sociologia descritiva. Para Hart (2009), sua análise não se interessa por o que a ciência sociológica tem a dizer sobre um determinado fenômeno. Seu objetivo é desvendar quais aspectos das práticas sociais influenciam nos conceitos e, portanto, contribuem para o esclarecimento de uma definição.

A distinção que Hart (2009) faz dos conceitos de "ser obrigado a" e "ter a obrigação de". Hart (2009) afirma que só se diz que alguém foi obrigado a alguma coisa quando havia uma ameaça envolvida que era grave e provável o bastante para tê-lo feito agir contra a sua vontade e quando a pessoa efetivamente agiu de acordo com a orientação de quem a obrigou a fazê-lo. De outra maneira, é possível que se tivesse a obrigação de fazer alguma coisa, mesmo na ausência de qualquer ameaça e mesmo com o fracasso em se cumprir a obrigação.

Hart (2009), portanto, faz uma análise das condições de uso de uma expressão ou de outra. A análise afirma que o conceito de "ser obrigado a" depende de uma ameaça concreta enquanto que "ter a obrigação de" não depende de ameaça concreta e depende de um plano normativo.

Reforça que o conceito de sociologia descritiva em nada se relaciona com a Sociologia enquanto ciência pelo fato de nenhuma pesquisa e análise de dados e estatística são necessárias para se chegar às conclusões que Hart (2009) se propõe. Somente é necessária uma construção coerente a partir de exemplos em que essas expressões são usadas. Desse modo, conclui-se que a sociologia descritiva e sua jurisprudência analítica são influenciadas pela filosofia analítica da linguagem.

Portanto, tomando como premissa o que Hart não possui objetivo de somente evidenciar a importância da validade e o reconhecimento da autoridade na fórmula do Direito. Hart (2009) formula seu pensamento como forma de ir além aos conceitos do positivismo jurídico. Sua intenção seria elucidar de forma linguístico-conceitual para sistematizar o 
Direito. Portanto, Hart (2009) é fortemente influenciado pela filosofia analítica da linguagem. Por isso, ele se diferencia em sua visão do Direito como um positivista analítico.

\section{CRÍTICAS DE HART A JOHN AUSTIN}

À época em que Hart (2009) escreveu o Conceito do Direito, o pensamento jurídico anglo-saxão era dominado por um positivismo jurídico que era chamado de imperativismo, que teria raízes na tradição utilitarista de Jeremy Bentham, e que se define melhor no pensamento de John Austin.

O jurista John Austin viveu e escreveu sua obra no século XIX, enfatiza-se que ele não é John L. Austin, filósofo da linguagem e contemporâneo de Hart. É com alvo no pensamento do John Austin, o jurista imperativista, a quem Hart (2009) as voltará suas críticas.

Hart tenta de uma maneira bem detalhada e minuciosa contradizer os argumentos feitos por John Austin, é com essa intenção que ele se ocupa dos capítulos II, III, IV do seu livro "O Conceito do Direito". A intenção de Austin em “The Province of Jurisprudence Determined" é dar um conceito ao Direito voltado a interpretá-lo como um conjunto de comandos e hábitos. Hart (2009) dedica-se a pormenorizar as críticas a Austin e assim desenvolver a ideia de um Conceito de Direito como um conjunto de regras primárias e secundárias.

O Direito em Austin (1998) seria comparado a um conjunto de comandos baseados em ameaças. Um exemplo que pode ser dado de como o Direito funcionaria nessa concepção é o de que os comandos poderiam ser postos em comparação com o que um assaltante diz ao caixa do banco para que assim ele o entregue o dinheiro, pois, caso contrário, ele atirará.

A única diferença entre o comando de um assaltante e os comandos feitos pelo Direito está em seu grau de atuação, contudo, a sua natureza de dever de obediência persistem sendo os mesmos na definição de John Austin.

Esses tipos de comando são ordenados do soberano ao seu súdito, tomando por referência o fato de os soberanos serem aqueles que não são comandados por ninguém. Portanto, os juízes aplicam os comandos do soberano, somente caso um soberano não tenha sido capaz de prever as circunstâncias de um caso é que seria permitido aos juízes decidirem com sua própria conveniência.

Hart (2009) prossegue definindo o que seria o comando por definição, comandar não seria uma palavra habitual fora do meio militar, ela denota fortemente a existência de uma 
organização hierárquica relativamente estável de homens, como poderiam ser um exército ou um grupo de discípulos, na qual o comandante seria aquele que ocuparia uma posição proeminente.

Hart (2009) dá exemplos de reais comandantes no momento em que cita o exemplo militar do general, que é quem comanda e quem profere os comandos dentro de uma organização militar. Embora isso possa ser dito também de um comando especial, mais guiado pelo carisma, em Cristo, que como é citado no Novo Testamento, comandaria os seus discípulos.

A primeira incoerência tratada por Hart ocorre porque a ideia de comando é usada equivocadamente por John Austin. Não necessariamente em um comando existe a ameaça latente de um dano em caso de desobediência. A posição de comando se caracteriza pelo exercício da autoridade hierárquica entre os homens, não pelo seu poder de infligir dano. $\mathrm{O}$ comando é, antes de qualquer coisa, uma chamada ao respeito pela autoridade, não um estímulo ao medo.

Dessa forma, o exemplo dado por Hart (2009) do assaltante estaria bem longe de uma ideia de comando, e sim bem mais próxima do imperativo de ordem, que caso não seja obedecida, acarreta em dano, em punição ao desobediente. Por isso Hart (2009) afirma que o que Austin (1998) equivocadamente compreende por comando poderia ser muito melhor traduzido como uma ordem jurídica.

Ao contrário, uma regra é uma afirmação sem qualquer relação pessoal, ela não dá ordem ou proibição a uma pessoa específica, como o comando faz. Uma regra torna uma conduta abstrata obrigatória, proibida ou permitida para pessoas indeterminadas e durante um tempo indeterminado, até que outra regra venha tomar o seu lugar.

De acordo com Hart (2009), quando uma regra é emitida, ela se torna tão abstrata e impessoal que não depende de vínculo com o seu criador, podendo se voltar contra o seu criador caso ele a descumpra. Uma regra pode até conter a ameaça, a sanção caso seja descumprida, contudo, não é a sanção que traz a validade a essa regra, de fato, sua validade existe quando há o reconhecimento de que essa regra é válida.

Dessa forma, Hart (2009) pretende provar que a fórmula de Austin para o Direito, em ter um comando garantido por ameaça é incapaz de fazer um real conceito de Direito. De fato, as normas jurídicas não podem ser compreendidas por meio de imperativos pessoais e 
hierarquizados com ameaça de dano. As normas jurídicas possuem características opostas a essa compreensão.

Elas são impessoais, são abstratas e gerais. Isto é, como não dependem de seus criadores, funcionam independentemente de tempo e lugar e seu dever de obediência não se deve ao reconhecimento de uma personalidade de comando, mas sim sob uma formulação reconhecida e que de modo oficial e que é aplicada a todos. O fundamento da validade é o reconhecimento, não se poderia entender as normas de Direito tendo como fundamento ameaças e o dano como consequência.

Hart (2009) afirma que as normas de Direito possuiriam um sentido interno e externo. O sentido externo consiste em padrões repetidos e uniformes, tornando assim uma conduta previsível. O exemplo que Hart (2009) dá é o de que os ingleses costumam ir ao cinema uma vez por semana. Eles não seguem uma regra por obediência e obrigação de ir ao cinema, mas é uma conduta repetida e previsível. Esse seria o sentido externo da regra, ela rege um comportamento previsível apenas para quem observa e não para quem a pratica, não é uma regra internalizada no sujeito.

De acordo com Hart (2009), uma diferença acontece com a regra de que os ingleses devem pagar impostos. O ingleses repetidamente e previsivelmente pagam seus impostos, por isso essa regra persistiria com seu sentido externo. Entretanto, não existem somente esse sentido, os ingleses pagam seus impostos também porque existe uma regra que estabelece essa conduta como obrigatória, ou seja, existe uma regra que obriga que os ingleses assim o façam, é uma obrigação imposta como regra. O sentido interno que as regras podem ter é de que a ideia de obrigatoriedade e de que uma norma deve ser obedecida porque é válida.

Para Hart (2009), existem três elementos que definem o sentido interno de uma regra. Os agentes reconhecem essa regra como obrigatória, os agentes que desobedecem à regra se tornam passíveis de crítica e de sanção e o motivo que justificaria essa repreensão é o próprio descumprimento da regra por si mesmo.

Uma pessoa que não vai ao cinema semanalmente na Inglaterra, no máximo sofreria uma repreensão moral por não estar cumprindo seu momento de lazer. No caso de não pagar impostos, está descumprindo uma obrigatoriedade que está objetivamente prevista em forma de regra. Como a regra é objetivamente posta, não são necessárias justificativas morais para essas regras, não se deve pagar imposto por ser bom ou ruim, mas sim pelo simples fato de ser uma regra. Essa é a maneira que Hart (2009) se opõe à ideia de Austin (1998) de o Direito ser 
formado por um conjunto de comandos e hábitos. Sendo essa a visão formalista própria do positivismo jurídico

Portanto, conforme afirma Peruzzo (2018), o ponto de vista interno de uma regra considera a perspectiva do agente, que aceita o modelo de comportamento estabelecido por uma regra e o entende da maneira posta por ele. O ponto de vista externo não depende da aceitação do agente, ele consiste em um padrão aceito por um observador externo que registra as práticas sociais generalizadas, ou seja, as regularidades comportamentais.

Hart (2009) aprofunda sua rejeição a ideia de o Direito ser formado por um conjunto de comandos, que somente podem ordenar ou proibir. Hart (2009) afirma que regras poderiam ir além e também possuem a função de permitir condutas e organizar atividades. As chamadas liberdades negativas, próprias do século XIX e início do liberalismo político se encaixam no paradigma hartiano.

Outras normas seriam responsáveis por organizar atividades, como por exemplo o procedimento em que um contrato deve ser realizado. Caso não se siga a regra, não há uma sanção específica, apenas tornará o contrato inválido. Seguindo-se os procedimentos como previstos na regra, o contrato terá validade, isto é, valor jurídico a ser alcançado. Portanto, nem todas as normas são necessariamente compostas de sanções.

A composição de Austin (1998) de um Direito como comando garantido por ameaça é simplista, visto que ela é incapaz de explicar as normas jurídicas e que essa definição seria suficiente apenas para casos de normas imperativas, mas seria incapaz de explicar regras que não ordenam nem proíbem, mas que permitem e organizam. A forma correta de nomeá-los não deve ser como comandos, mas sim sob o conceito de regras, que não necessariamente são garantidas com base em ameaças.

A ideia de Austin de o Direito ser formado por um soberano e um súdito também é pormenorizada e contradita por Hart (2009) em seu capítulo IV. Súdito seria o que tem por hábito obedecer a um soberano, enquanto que o soberano seria aquele que embora sendo obedecido, não teria o hábito de obedecer ninguém. Para refutar essa ideia, Hart (2009) afirma que a definição dada para um soberano supõe um tipo de governante absoluto que não teria vez nas modernas democracias, porque nelas, o governante também é submetido às leis ordinárias e à Constituição e deve seguir regras sem ultrapassar o que designado por essas mesmas regras. Hart (2009) afirma que nas democracias os governantes agem como representantes do povo, que seria o verdadeiro soberano. 
Conforme pontua Peruzzo (2018), Austin forma seu conceito de Direito baseado na ideia de que o soberano e sua corte estão acima de seus súditos e podem, caso necessário, expandir ou reduzir suas liberdades.

Para contrapor essa ideia, Hart (2009) propõe uma sociedade que possui um sujeito chamado "Rex" no poder. O exemplo hartiano é de uma sociedade democrática em que o soberano impõe obrigações a serem seguidas coercitivamente. Inicialmente nesse reinado, surgiriam complicações a respeito do desejo de desobediência e do medo de sanções, que eram legítimos, porque eram originados da vontade do soberano. Com o tempo, essa sociedade começa a cumprir suas leis; um trabalho inicialmente incomum torna-se um comportamento padrão por meio da formação do hábito.

Nesse caso, a soberania poderia legitimar um hábito que seria amplamente obedecido por seus súditos, tornando a lei constitucional de acordo com os valores legitimados pelo hábito. Hart (2009), prossegue com sua exemplificação no sentido de que caso Rex I morra, seu herdeiro Rex II assumiria o poder, o ponto questionado é se as regras teriam o hábito e persistiriam no tempo, independentemente de governante.

Hart (2009) afirma que anteriormente a ordens e comandos impostos pelo soberano anterior foram impostas pela força do hábito e eram obedecidas pela sociedade. Entretanto, a morte de Rex I autorizou seu sucessor a ter poder e legislar, mas isso não garantiria de maneira alguma que a sociedade o obedeceria, levando em consideração que seu modelo de governo não era baseado em regras que justificassem essa obediência, apenas em comandos e hábitos.

Isso demonstra que Rex II não herdou realmente o poder feito por seu pai, portanto Rex II seria um soberano e legislador com seu poder ameaçado pela instabilidade desse sistema de leis. De acordo com Hart (2009), o simples fato de que existia um hábito generalizado de que a obediência a Rex I durante a sua vida não faz com que seja suscetível que Rex II será obedecido com o mesmo hábito. Não existe nada que sequer justifique e legitime o seu poder.

Dessa forma, as ideias de soberano e de súdito acabariam por se confundir entre si, de modo que não faria sentido distingui-las de modo fechado, como Austin (1998) o fizera. Uma definição tão pessoal de soberano e súdito não é coberta pela definição do Direito em si mesmo, porque os soberanos e os súditos variam ao longo do tempo, o que não acontece com o Direito. Normas e regras podem perdurar décadas como válidas até o momento em que 
forem revogadas, mesmo que os seus criadores e as pessoas que eram objeto dessas normas tenham morrido ou perdido o poder.

Como comandos são extremamente pessoais, eles não poderiam ultrapassar a pessoa do comandante, e só uma regra seria plenamente capaz de explicá-lo. Somente a noção de regras, objetivas, abstratas e impessoais é capaz de explicar o fenômeno do Direito em Hart (2009).

A noção de hábito em Austin (1998) também é detalhadamente criticada, de forma que o súdito seria aquele que costuma obedecer às ordens do comandante, a crítica residiria no fato de esse conceito não apontar se o súdito deve ou não obedecer o que o soberano comanda.

A norma perde o seu fundamento de obrigação e passa a ser somente uma exterioridade. Somente uma regra seria capaz de explicar a obrigação que existiria no Direito. De acordo com Hart (2009), Descrever um comportamento por padrões habituais é reduzi-lo somente ao que é observado, com o seu caráter externo, ignorando o sentido interno que uma regra pode ter.

Portanto, a definição de Austin sobre o direito seria simplista e não reconheceria as características que as normas poderiam ter, muito menos dariam espaço para um caráter mais complexo de normas interrelacionadas e sistematizadas. É a partir dessa tentativa de dar ao Direito um caráter mais complexo que Hart formará o seu conceito de Direito como um sistema amplo de regras interligadas.

\section{A FORMAÇÃO DAS REGRAS PRIMÁRIAS E SECUNDÁRIAS EM HART}

Após ter feito críticas diretas ao modo como Austin (1998) enxergaria o Direito, Hart (2009) busca desenvolver o seu conceito de Direito baseado em um sistema de Regras. Hart (2009) entende que não haveria outra maneira de explicar e fundamentar o funcionamento das normas jurídicas.

Hart (2009) imagina analiticamente uma comunidade pequena e pouco complexa em que as únicas regras que existem são as que se relacionam a condutas, sendo elas quem permite o que se faz ou se deixe de fazer. Essas regras, que regulariam diretamente as condutas, Hart (2009) chama de "regras primárias". Uma comunidade pequena e pouco complexa pode passar muito bem dispondo apenas de regras primárias, que, contudo, seriam normas incertas, estáticas e ineficazes. 
Hart (2009) desenvolve essa ideia afirmando que conforme a comunidade cresça e se torne mais complexa, ela tende a se deparar com três tipos de problemas. O primeiro, Hart chama de o problema da incerteza, porque ao longo do tempo, as regras da comunidade mudaram e se multiplicaram. Os membros da comunidade já não saberiam quais regras seriam válidas ou não.

O segundo problema é chamado por Hart (2009) de do caráter estático das regras. Essa comunidade não dispõe de formas institucionais de criar novas regras e de fazer outras deixarem de existir, o que dificulta sua adaptação às novas circunstâncias e desafios com que se confronta.

O terceiro problema é chamado por Hart (2009) de problema da ineficácia. Seja como produto do caráter estático das normas, seja como produto da perda de prestígio das autoridades tradicionais e dos costumes, cresce nessa comunidade o número de casos em que os membros não cumprem com as regras válidas e obrigatórias, de modo que estas vão se tornando cada vez mais apenas palavras vazias que nada conseguem produzir na realidade.

Hart (2009) prossegue com sua ideia de uma sociedade inicial sugerindo que a comunidade teria que recorrer a um segundo tipo de regras, que não seriam mais regras primárias, que são as regras que regulam a vida diretamente, mas sim viu-se a necessidade de regras que fundamentassem a própria existência de regras e as organizassem em um sistema racional.

De acordo com Gardner (2013) a ideia de como Hart conceberia a evolução do Direito seria em realidade uma fábula. Hart apenas a usaria para ilustrar o seu argumento, mas que não possuiria qualquer vínculo com a realidade. Por isso, Gardner chama a ideia de "fábula de Hart".

De acordo com a interpretação de Neil MacCormick (2008), a descrição de Hart (2009) sobre essa sociedade inicial não corresponde a um fato histórico de como as sociedades primitivas passaram do estado pré-jurídico para o jurídico. Segundo a interpretação de MacCormick (2008), Hart faz uma construção presumida no momento em que a sociedade já se encontrava constituída somente como uma fórmula de elucidar e explicar melhor o seu ponto, que seria de como as sociedades se tornam mais complexas através de um sistema de regras. 
Segundo a interpretação Coelho (2014), a fábula de Hart não passa de um experimento mental sem qualquer intenção de ter um sentido histórico. Hart (2009) não se importaria com questões empíricas, mas sim em servir aos propósitos de sua tese teórica e prática.

Na visão de Coelho (2014), Hart faria em realidade o oposto, tornaria a sua sociedade hipotética bastante diferente das reais sociedades primitivas, porque o foco seria em fazer um paralelo com a sociedade contemporânea em advertir o que aconteceria caso não se valorizassem as regras secundárias e se desconsiderassem os fatores que dão validade às normas.

A esse tipo de regras, Hart (2009) dá o nome de regras secundárias, ou seja, as regras que originam outras regras. Cada tipo de regra se voltaria para resolver os problemas causados pela existência somente de regras primárias.

Portanto, as regras secundárias seriam as regras responsáveis por conferir legitimidade aos poderes em geral. Porém, para elas existirem, é necessário que existam regras primárias, criando um sistema de regras interdependente.

Portanto, para MacCormick (2008), o exame de Hart se dá em uma imaginação de o que uma sociedade contemporânea à sua faria em caso se deixasse de existirem regras secundárias e de que modo as regras primárias perderiam sua essência.

Hart (2009) afirma que a solução para cada um desses problemas apresentados nessa estrutura social consiste em suplementar as normas primárias de obrigação e normas secundárias. A introdução para a correção dos defeitos seria responsável por uma transição entre o mundo pré-jurídico para o mundo jurídico. Segundo Hart (2009), cada recurso corretivo traria muitos dos elementos que compõem o Direito.

Combinados, os três recursos converteriam um sistema que funcionava unicamente em normas primárias em um complexo sistema jurídico.

Uma regra secundária importante para o entendimento do pensamento de Hart (2009) são as que ele denomina como "regras de reconhecimento", que são incialmente explicadas por ele da seguinte maneira:

\footnotetext{
A forma mais simples de solução para a incerteza própria de um regime de regras primárias é introdução de algo que chamaremos de "regra de reconhecimento". Essa norma especifica as características que, se estiverem presentes numa determinada norma, serão consideradas como indicação conclusiva que se trata de uma norma do grupo, a ser apoiada pela pressão social que exerce. A existência dessa norma de reconhecimento pode assumir qualquer uma dentre uma imensa variedade de formas, simples ou complexas. (HART, 2009, p. 122).
} 
Com o intuito de acabar com toda incerteza possível, a comunidade instituiria um modelo recorre ao que Hart (2009) denomina como "regra de reconhecimento", que instituiria um critério formal para decidir se uma regra é válida ou não.

De acordo com Hart (2009), como nos estágios primitivos do Direito de muitas sociedades, essa regra de reconhecimento poderia não passar de uma lista ou um texto que estivesse revestido de autoridade que constasse em algum documento escrito ou que estivesse gravado em algum monumento público.

Conforme explica Hart (2009), conforme os sistemas jurídicos se tornem mais complexos, mais complexas e diversas se tornam as regras de reconhecimento. Existindo, portanto, diversas fontes do Direito.

Essa transição do mundo pré-jurídico ao mundo jurídico é definida por Hart (2009) como etapas em que haveria a transcrição e objetivação de normas até então conservadas apenas sob a forma oral. Entretanto, a mera transcrição é insuficiente para que Hart (2009) as defina como regras de reconhecimento. O fator realmente importante para o conceito de Hart seria a obrigatoriedade de se considerar a inscrição ou a norma escrita como fonte da autoridade.

Para acabar com o problema do caráter estático, a comunidade recorreria a regras de modificação, que definem quais pessoas são dotadas de autoridade e responsáveis por criar novas regras e por fazer antigas pararem de existir, também devem definir qual o procedimento a ser seguido para que essa modificação ocorra sem que se tenha a incerteza de que algumas regras persistem vigentes e outras não.

As regras de modificação seriam as responsáveis por conceder poderes a órgãos para que modifiquem, retirem ou coloquem novas regras ao sistema jurídico. Seriam regras responsáveis por regular que o Direito se modifique com o tempo. Elas possuem uma grande ligação com as regras de reconhecimento, visto que precisam de alguma norma que as confira identidade e validade.

Com a intenção de acabar com o problema da ineficácia das regras, a comunidade recorreria a "regras de aplicação", que definiriam quem são as pessoas dotadas de autoridade e responsáveis por julgar as controvérsias que surgirem entre os membros da comunidade e de imporem suas decisões, caso seja necessário, mediante o uso de uma coerção organizada, limitada pelas leis. 
Dessa forma, os três tipos de regras secundárias, regras de reconhecimento, regras de aplicação e regras de modificação, resolveriam os três problemas com regras elencados anteriormente. Dessa maneira, poderiam se desenvolver como sociedade mais complexas com um desenvolvido sistema de regras.

Portanto, para Hart (2009), o melhor conceito que se pode dar ao Direito é um conceito que considere uma União entre regras primárias e secundárias, em um sistema com vários níveis de regras e autorregulado.

Dos três tipos de regras secundárias, o que tornou Hart (2009) mais conhecido foi a regra de reconhecimento. Sendo um método formal para decidir se uma regra é válida ou não. Dando ênfase à importância da validade da norma, Hart (2009) possui características do positivismo jurídico exclusivo.

Hart (2009) prossegue afirmando que as regras de reconhecimento possuem muitos elementos característicos do Direito por colocar às normas jurídicas o selo de autoridade. Elas representariam um modelo embrionário de um sistema jurídico, pois não constituiriam elementos isolados e desconexos, mas se encontrariam unificados em uma interrelação.

Dizer que determinada regra é válida equivale a reconhecer que esta satisfaz a todos os critérios propostos pela norma de reconhecimento e é, portanto, uma norma do sistema. Na verdade, pode-se simplesmente dizer que a afirmação de que certa norma é válida significa que tal norma satisfaz a todos os critérios oferecidos pela norma de reconhecimento (HART, 2009, p. 133).

O importante para uma regra de reconhecimento é saber se uma regra jurídica foi produzida por alguém que tenha autoridade para tanto. Eis, portanto, porque toda regra presente nesse sistema adquire validade com base na regra de reconhecimento. Uma regra de reconhecimento não precisa ser válida, a necessidade em cima dela é de ela ser aceita, sendo reconhecida e obedecida pela comunidade.

Portanto, uma regra de reconhecimento funciona como uma norma última, isto é, aquela que é verificada para ser devidamente uma regra de reconhecimento. Podem existir conflitos de regras de reconhecimento, para Hart (2009) esses critérios devem ser resolvidos por critérios hierarquizados por ordem de subordinação e primazia relativa em que um deles seria considerado o supremo.

Hart (2009) considera que um critério de validade jurídica ou de fonte do Direito é supremo se as normas identificadas mediante referência a ele são ainda reconhecidas como 
normas do sistema mesmo que conflitem com normas identificadas mediante referência aos outros critérios.

Dessa maneira, para Hart (2009), para se identificar uma norma primária de obrigação, deve ser aceita e utilizada uma norma de reconhecimento. Essa definição é o fundamento de um sistema jurídico. Portanto, um sistema jurídico para Hart (2009) somente pode ser compreendido como um sistema completo de normas em que sua interrelação é sua essência.

Hans Kelsen (2009) busca definir a Ciência do Direito como o estudo de um objeto fixo, que é a norma jurídica. Todo o seu estudo se volta para destrinchar as características das normas jurídicas e a sua validade. Com esse objetivo, Kelsen (2009) desenvolve um ordenamento jurídico baseado na ideia de uma hierarquia de normas, construindo a ideia de uma norma fundamental como base desse ordenamento.

Hart (2009) não nega a importância da validade para a existência de uma norma jurídica. Contudo, seu conceito busca desenvolver o conceito de Direito que seria maior do que reduzi-lo ao estudo da norma isolada. Sua intenção é mostrar a interrelação entre as normas e demonstrar como o Direito é, por definição, um sistema de regras.

Hart (2009) também busca definir o Direito de uma maneira mais ampla ao afirmar que os fundamentos de um sistema jurídico são as relações entre regras primárias e regras secundárias, tendo as regras de reconhecimento um destaque por conferirem validade às demais normas. Portanto, enquanto a norma fundamental é pressuposta, o sistema de regras hartiano é posto e fático.

Conforme Simioni e Barbosa (2016), outro fator de diferenciação é o fato de a norma fundamental ser única, enquanto as regras de reconhecimento podem ser várias. Sendo essa pluralidade de normas a responsável por conferir legitimidade às demais normas.

A existência do Direito depende de fatos empíricos e aceitação da comunidade, pode ser uma norma jurídica, pode ser autoridade sobre as demais regras e pode ser uma norma com força jurídica. Todos esses conceitos são dependentes de uma facticidade sociológica, isto é, Hart (2009) faz uma visão sociológica descritiva sobre o conceito de validade no Direito.

\section{CONCLUSÃO}


Herbert Hart é a grande referência para a jurisprudência analítica de tradição anglosaxã. Suas ideias formaram uma Teoria do Direito baseada em um positivismo analítico. Seus conceitos basearam-se em uma filosofia da linguagem para descrever um sistema complexo de regras que se justificava pela ideia de validade.

Para entender a perspectiva de Hart sobre o Direito, é necessário que se entenda o pensamento no qual ele se baseia. A grande influência para Hart foi a filosofia analítica da linguagem.

Para entender a perspectiva de Hart sobre o Direito, é necessário que se entenda o pensamento no qual ele se baseia. A partir da filosofia analítica da linguagem, Hart propõe a abordagem de uma sociologia descritiva do Direito, o que não deve ser confundido com a Sociologia enquanto área do conhecimento, com rigor metodológico e requisito de atividade empírica. Hart se propôs a descrever conceitos que se baseassem em práticas sociais.

A filosofia analítica da linguagem que influenciou Hart acreditava que toda linguagem está estreitamente ligada com uma prática. Não existe um conceito abstrato e inatingível, todos os conceitos são reconhecidos a partir de alguma ligação com a realidade. Para explicar o Direito e seus conceitos, Hart necessita vincular sua abordagem à práticas sociais facilmente reconhecíveis.

Hart se ocupa dos capítulos II a IV de seu conceito de Direito para refutar o pensamento de John Austin, jurista do século XIX, que afirmava que o Direito seria um conjunto de ordens e ameaças. Deve-se seguir o ordenado sob pena de sanção, feita por um soberano aos seus súditos. Esse foi o grande alvo de Hart, para quem essa seria uma redução simplista do conceito de Direito.

Para Hart, a ideia de um comando pressupõe uma pessoalidade, uma autoridade carismática, e por isso não é necessário que se cause alguma espécie de dano. Apenas se reconhece a autoridade. A noção de referência a um real conceito de Direito estaria nas regras.

Uma regra não possui essas falhas, ela é impessoal e abstrata, podendo ser usada contra seu criador. Não é necessário que uma regra tenha sanção, sua validade depende do reconhecimento de sua legitimidade. Regras sim seriam essencialmente formadoras do Direito e não teriam somente o caráter imperativo, regras poderiam permitir condutas e organizar atividades. Direitos fundamentais são regras permissivas enquanto que regras administrativas para a organização do Estado são regras que se enquadram nesse segundo paradigma hartiano. 
A ideia de Austin falha no sentido de que as regras são impessoais, dependem de um reconhecimento interno para serem cumpridas e não se reduzem a regras com sanções. É para demonstrar como o Direito é um conjunto de regras interrelacionadas que Hart vai montar o seu sistema de regras.

Após as críticas a Austin, Hart busca o conceito de Direito baseado em um sistema de Regras. Hart entende que não haveria outra maneira de explicar e fundamentar o funcionamento das normas jurídicas.

Para exemplificar a necessidade de um sistema complexo de regras, Hart imagina uma sociedade pouco complexa que regula somente condutas, essas regras Hart chama de "regras primárias". Conforme a comunidade se tornasse mais complexa, surgiriam problemas complexos a serem resolvidos.

Os problemas são chamados por Hart de problema da incerteza, do caráter estático das regras e do problema da ineficácia. O primeiro é sobre a incerteza ao longo do tempo sobre quais regras se modificaram e quais permanecem válidas. O segundo problema consiste em a comunidade não ter uma instituição definida para criar novas regras e revogar as anteriores. $\mathrm{O}$ terceiro problema é definido como a problema da ineficácia, em que Hart afirma que na comunidade as regras não seriam cumpridas por ninguém as reconhecer como válidas, por não existir uma autoridade definidora das regras como tais.

Esses problemas da sociedade imaginada por Hart seriam resolvidos com a formação das chamadas regras secundárias, que seriam regras que originariam outras regras. Para acabar com o problema do caráter estático, a comunidade se utilizaria de regras de modificação. Seriam regras que definiriam e tornariam objetivos o procedimento para se modificar, retirar ou colocar novas regras. Essas regras regulam a modificação do Direito. O problema da ineficácia é resolvido por o que Hart define como regras de aplicação, que são regras responsáveis por definir quais pessoas seriam dotadas de autoridade entre os membros da comunidade. Seriam, portanto, regras que definiriam de onde emergiriam poderes e sanções. O último problema é resolvido regra secundária mais famosa em Hart são as regras de reconhecimento, que resolveriam os problemas da incerteza. Isso ocorre porque as regras de reconhecimento definem o procedimento para se reconhecer a validade de uma regra. Uma regra só é válida se passar por um trâmite que defina e reconheça sua autoridade. A regra que define a autoridade de uma outra regra chama-se regra de reconhecimento. 
Para Hart, o Direito depende e é unificado com um interrelação entre regras primárias e regras secundárias. As regras primárias só funcionam em sociedades complexas aliadas a regras secundárias, e as regras secundárias por si mesmas perdem a razão de existir. Pode-se compreender que o fundamento para um sistema jurídico em Hart é um sistema complexo de regras. O Direito é um sistema de regras.

O trabalho conclui que ao tomar como premissa a filosofia analítica da linguagem e se utilizar de uma sociologia descritiva, Hart monta uma elaborada e minuciosa visão para exemplificar como o seu conceito de Direito fundamenta-se em um sistema de regras. Hart toma como premissa exemplos práticos para criticar a visão de Austin sobre o Direito ser formado por ordens de comando e ameaça para afirmar que em realidade ele é formado por regras. Novamente, ao definir as regras primárias e secundárias, Hart parte das práticas sociais de uma sociedade imaginada para defender e elaboração de um sistema de regras.

\section{REFERÊNCIAS}

AUSTIN, J. L. How to do things with words. Oxford: Clarendon Press, 1982.

AUSTIN, John. The Province of Jurisprudence Determined - and The Uses of the Study of Jurisprudence. Indianapolis: Hackett Publishing Company, 1998.

COELHO, André. Por que Surgem as Regras Secundárias? Uma reinterpretação da fábula de Hart. REVISTA DA FACULDADE DE DIREITO DA UERJ- RFD- v. 1, n.25, 2014.

COTTERRELL, Roger. The politics of jurisprudence. A critical introduction to legal philosophy. Londres e Edimburgo: Butterworth, 1989.

GARDNER, John. Why law might emerge: Hart's problematic fable. Legal Research Paper Series, University of Oxford, n. 61, May 2013.

HART, Herbert L.A. O Conceito de Direito. São Paulo: Editora Martins Fontes, 2009.

KELSEN, Hans. Teoria Pura do Direito. São Paulo. Martins Fontes. 2009.

MACCORMICK, Neil. H. L. A. Hart. 2. ed. Stanford, CA: Stanford University Press, 2008.

PABLOS R., Mayara. As Contribuições de Wittgenstein para a Filosofia do Direito: uma análise da linguagem e suas regras. 125f. Dissertação (Mestrado em filosofia. Florianópolis, SC, 2013.

SIMIONI Rafael Lazzarotto e BARBOSA, Rodrigo Pedroso. Regras de Reconhecimento e a Legitimidade da Decisão Jurídica em Hart. Revista Debates, Porto Alegre, v. 10, n. 3, p. 153168, set.-dez. 2016. 
STOLZ, Sheila. Um Modelo de Positivismo Jurídico: O Pensamento de Herbert Hart. Revista Direito GV. v. 3. n. 1. P. 101-120, jan-jun, 2007.

WITTGENSTEIN, Ludwig. Investigações Filosóficas. Petrópolis: Vozes, 2008.

Tratado Lógico-Filosófico. Investigações filosóficas. $2^{\mathrm{a}}$ ed. Lisboa: Calouste Gulbenkian, 2002. 